\title{
The Evaluation of Factors Affecting the Pre-Swim Shower Behaviors of Pool Patrons
}

\author{
Andrew Low ${ }^{1}$, Helen Heacock ${ }^{2}$ \\ ${ }^{1}$ Lead author, B. Tech Student, School of Health Sciences, British Columbia Institute of Technology, 3700 Willingdon Ave, Burnaby, BC V5G 3H2 \\ ${ }^{2}$ Supervisor, School of Health Sciences, British Columbia Institute of Technology, 3700 Willingdon Ave, Burnaby, BC V5G 3H2
}

\begin{abstract}
Background: The hygiene practices of pool patrons are important in maintaining water quality as well as patron health and safety. Poor practices, such as not taking a pre-swim shower, can introduce additional contaminants, which will then react with the free available chlorine to form disinfection by products (DBPs). Not only will excess contaminants decrease the free available chlorine but it will also cause a copious amount of DBPs to be formed. DBPs are known to cause eye and skin irritation, an unpleasant odor, and may cause additional respiratory issues. Therefore, in the interest of public health the number of contaminants introduced into the water should be minimized, which can be done through improving the hygiene practices of patrons. This study investigated factors that may affect pre-swim shower frequencies among aquatic facility patrons.
\end{abstract}

Methods: Data from 78 respondents to a self-administered electronic survey were used in this study. The survey evaluated respondents' knowledge of pool related illnesses, knowledge of proper aquatic facility hygiene practices and their attitudes toward these practices. Results were analyzed using one-way ANOVA, chi squared test and independent samples t-test.

Results: The only statistically significant relationship found was an association between the how often an individual used aquatic facilities and their pre-swim shower frequency; frequent aquatic facility users were found to rarely/never take a pre-swim shower $(\mathrm{p}=0.049)$. As well, factors such as knowledge of pool related illnesses, knowledge of proper hygiene practices, age, and if an individual had read the pool rules were not found to be related to pre-swim shower frequency.

Conclusion: The results indicate that educational campaigns aimed at increasing the public knowledge of pool related illnesses and proper pool hygiene practices may not increase pre-swim shower frequencies. Results from this study also indicate that if the showers were cleaner, warmer, and or more private, preswim shower frequencies may increase. As well, 79.5\% of respondents knew that taking a pre-swim shower is required and $52.6 \%$ of participants indicated that they would improve their hygiene practices if consequences were implemented. Taken together, this may suggest that the physical layout of the showering facilities within a swimming pool complex may influence showering behaviour, and greater enforcement of pool rules may be needed in order to increase pre-swim shower frequency.

Keywords: pool, aquatic facility, pre-swim shower, pool hygiene practices

\section{Introduction}

In many countries, swimming is a popular recreational activity that offers many health benefits. In Canada, swimming is the second most popular sport among children aged 5-14, eighth most among men, and first among women (1). With swimming and other aquatic activities being so popular, it is crucial that that the risks in aquatic facilities are minimized; in these environments there are physical, chemical, and biological hazards. One way that these risks are mitigated is through regular inspections by Environmental health officers (EHOs). For this purpose, in B.C., EHOs apply the Pool Regulation, which is under the Public Health Act. The Pool Regulation defines the type of facilities that will be inspected and the standards that must be maintained (2). The Pool Regulation clearly outlines the testing frequencies and required levels for disinfectants and various pool chemistry parameters. It is 
important that these standards are met as they ensure patron comfort and help to prevent the spread of communicable diseases (2).

Maintaining these standards can be quite difficult as pool water is affected by a variety of factors including bather hygiene (3). Some of these practices, such as swimming with a gastrointestinal illness, may lead to the transmission of communicable diseases; conversely, other practices, such as not taking a pre-swim shower, may seem inconsequential as pool water is treated. However, this is not true, as poor pool hygiene leads to an increase in contaminants in the water, which combine with the free available chlorine to form DBPs. Increased concentrations of DBPs are known to cause various deleterious health effects and may even contribute to the spread of communicable diseases as there is less disinfectant available (4). DBPs cannot be completely removed from the pool environment as a disinfectant residual is needed to inactivate pathogens as they are introduced into the water. However, their formation should be mitigated.

Given that pools are regulated by EHOs, swimmer hygiene would be of concern as poor hygiene may negatively impact public health. Therefore, it is important to understand why poor hygiene practices persist and to gather information on how best to improve these practices. One hygiene practice of particular interest is whether patrons take a pre-swim shower. Pre-swim showers are of particular interest because pathogens may be present on body surfaces and contaminants present on the body add to DBP formation. In the author's personal experience, through observation in his ten plus years of experience as a lifeguard, preswim showers are not a common practice.

\section{Literature Review}

\section{Hazards - Microbiological}

One reason good pool hygiene is encouraged is because poor practices may lead to pathogens being introduced into pool water. For example, pathogens can be spread through direct person to person contact or through the ingestion of pool water contaminated with fecal matter (5). Even though swimmers may not mean to release feces into the water, accidental fecal releases do happen. As well, people carry an average of $0.14 \mathrm{~g}$ of fecal matter on their perianal surface (6). Once these organisms are in the water, they may be ingested; research has shown that on average, a person will swallow $10-150 \mathrm{~mL}$ of water per hour, with children swallowing more than adults (7).

With proper disinfection, as mandated in the Pool Regulation, many of the pathogens of concern can be eliminated (5). However, poor maintenance by operators, such as failure to maintain an adequate concentration of disinfectant may lead to infection by these microorganisms (8). To gain insight into the magnitude of the issue, surveillance data from the Centers for Disease Control and Prevention can be examined. Overall, recreational water illnesses (RWIs) have been increasing over the past twenty years (3). Looking at data from 2010-2011, there were 69 reported outbreaks from treated water facilities; this led to 1,309 cases of RWI, 73 hospitalizations, and one death. Of the 69 outbreaks reported, 52\% were found to be caused by Cryptosporidium (9). As Cryptosporidium is resistant to disinfection by chlorine (5), this highlights the importance of not being reliant on chlorine based disinfection for swimmer safety but to stress other barriers to disease such as good patron hygiene (9).

According to the Centers for Disease Control and Prevention (CDC), the top five causes, in terms of frequency, of RWIs are Cryptosporidium, Psuedomonas, Shigella, Legionella, and Norovirus (10). Pathogens causing RWI can be split into two main groups, fecal related and non-fecal related. Within the fecal related group are Cryptosporidium, Giardia, Shigella, Escherichia coli O157:H7, norovirus, adenovirus, and Hepatitis A. These organisms cause a variety of gastrointestinal symptoms that range from very severe (E. coli O157:H7) to self-limiting (norovirus) and can all be passed through the fecal-oral route. In this group, Shigella, E. coli O157:H7, and Hepatitis A can be controlled by properly maintaining pool water. Conversely, Cryptosporidium, 
Giardia, and adenovirus are resistant to chlorine; Giardia and adenovirus are more susceptible and can be eliminated if the CDC's recommendations for responding to an AFR are followed (5).

Non-fecal related pathogens include

Pseudomonas aeruginosa, Legionella

pneumophilia, methicillin-resistant

Staphylococcus Aureus, Molluscum

contagiosum, papillomavirus, and Tinea pedis;

all of which, can be controlled for in a properly

maintained pool (5). These organisms cause a

variety of different illnesses, from ear infections

(e.g. P. aeuruginosia), pneumonia (e.g. $L$.

pneumophilia), and athlete's foot (Tinea pedis)

(5). All of these organisms, except for $L$.

pneumophilia, can be passed through contact with an infected person or contaminated surfaces such as pool equipment. For L. pneumophilia, this bacterium is spread through the inhalation of aerosolized contaminated water droplets, which may be caused by hot tub jets or other water play features (11).

\section{Hazards - Disinfection by Products}

DBPs, form when residual disinfectant reacts with organic compounds. This would include contaminants brought in by humans such as sweat, body lotions, urine, and cosmetics (12). As chlorine is the most common disinfectant, much of the research on the health effects of DBPs has focused on the compounds that form as a result of chlorine disinfection (5). The two main classes of DBPs are chloramines and trihalomethanes (THMs), both of which can enter the human body through inhalation, ingestion, and absorption. Chloramines consist of monochloramines, dichloramines, and trichloramines (13). Monochloramine and dichloramine are water-soluble so they can be ingested and absorbed; whereas trichloramines are not water soluble and can only be inhaled (14). THMs are a class of compounds, of which, chloroform is most commonly detected (13).

It is known that DBPs are eye and ear irritants $(4,14,15)$. However, there is mixed evidence regarding the effect of DBPs on the respiratory system. Notably, the evidence that there is an association between swimming in indoor pools and asthma rates in children is very strong (16). For example, a study of school aged children, reported a positive association between time spent at chlorinated pools and the risk of developing asthma (17). In other populations, such as high-level competitive swimmers, a higher prevalence of asthma and bronchial hyperresponsiveness was found in these athletes when compared to athletes in other sports (15). A study of recreational swimmers aged 18-55, also found that individuals who spent more time swimming in indoor chlorinated pools were more likely to develop bronchial asthma; this risk increased 5\% for every additional 5h/week per year spent swimming at indoor chlorinated pools (18).

As was mentioned above, not all studies found that increased DBP exposure led to harmful effects on lung function. One study on lifeguards found no association between bronchial hyperresponsiveness and exposure to DBP (15). Participants in this study had an average age of 36 for men and 32 for women and had been working as lifeguards for an average of 11 years for men and 8 years for women. It is important to note that the authors postulated that the cumulative exposure time may not have been long enough for the negative effects to have manifested. As well, the authors stated that the study may have been affected by selection bias. Lifeguards who may have developed respiratory problems may have already left the profession and therefore would not have participated in the study (15). However, another study found that lifeguards had significantly lower scores on pulmonary function tests when compared to control subjects (14). Although it is important to access the effects of DBPs on all populations, lifeguards may not be the most at risk population as research has shown that those who are actively inhaling chloramines and close to the surface of the water are at the greatest risk (16). As for other health effects, there is not a lot of available evidence linking exposure to DBPs to cancer. Researchers have stated that this relationship would be difficult to establish as water supplies are often chlorinated and pools all have different blends of DBPs (13). Overall, more studies need to be conducted and as one author pointed out, studies need to be conducted 
where the benefits of swimming are compared to the "deleterious effects of excessive exposure to chlorination products" (17).

\section{Pool Patron's Hygiene Practices}

Section 8(2)(a) of the Pool Regulation clearly states that individuals who are sick, have open sores, or discharge coming from their ears or nose are not allowed to enter the pool. As well, this section also states that a shower is a requirement before entering the pool (2). The $\mathrm{CDC}$ is even more specific, recommending practices such as hourly bathroom breaks for children and that diapers be changed in bathrooms or designated areas, away from the pool area (3). So that pool rules are clear, the Pool Regulation mandates that operators post pool rules in a "prominent position" within their premises (2).

Having the rules posted appears to be important as an Italian study found that good pool hygiene (taking a pre-swim shower, wearing footwear, and not urinating) were significantly correlated with reading the pool rules (19). This study found that $70.9 \%$ of participants took a preswim shower. Conversely, in the US, data indicates that only $44 \%$ of Americans view a pre-swim shower as necessary, only $32 \%$ of Americans said that they shower before entering the pool, and $19 \%$ admit to urinating in the pool. Interestingly, these numbers have increased when compared to data generated in 2009 (20).

Perhaps, there may be a cultural difference, as was stated by Lakind et al., the US has a culture that appears to "celebrate using the pool as a urinal" implying that swimmer hygiene is not taken seriously (13). However, studies need to be conducted on this topic and more research will be needed to understand if cultural differences affect swimmer hygiene. As well, this difference may not be due to cultural factors but could be a result of factors such as different pool design and layout. In the survey conducted within the US, study participants stated that if facilities were more accessible, private, and clean, they would be $31 \%, 35 \%$, and $38 \%$ respectively, more likely to take a pre-swim shower (20).

\section{Hygiene as a Protective Measure}

As was mentioned above, the Pool Regulation clearly states that a pre-swim shower is required (2). However, it does not stipulate how a shower should be taken. It is suggested that washing with soap and water is necessary to remove biological contaminants and other contaminants (deodorant, hair products, sweat, etc.) $(5,12)$. Highlighting the importance of taking a preswim shower, studies have shown that contamination from a single swimmer can be reduced $35-60 \%$ (13). As well, it appears that showers do not have to be long, as one study showed that most contaminants are released within 60 seconds. This study also confirmed that scrubbing will help remove material from the body. Unfortunately, it was not stated if showers were done with or without soap. This study also demonstrated that showering without a bathing suit may be necessary to remove fecal associated pathogens such as E. coli and intestinal enterococci (4). Overall, this study demonstrated that showering helps to decrease the number of contaminants, introduced into pool water, which will lead to less DBPs.

\section{Predictors of Good Pool Patron Hygiene}

Before looking at factors that are linked to improved pool patron hygiene, interventions targeted toward reducing population salt intake will be examined as this area receives greater attention and funding. In a systematic review, data from 22 studies were compiled and the authors concluded that "the implementation of education and awareness-raising interventions alone are unlikely to be adequate in reducing population salt intake to the recommended levels" (21). Looking at the 22 studies themselves, 19 showed significant decline in salt intake when interventions were implemented. However, retrospectively, the authors identified that these studies suffered from biases (21). Even so, this is evidence that education or awareness based interventions are somewhat effective in modifying behavior. It has been suggested these interventions could be made more effective by making directions more specific and using a variety of approaches (6). 
As for modifying pool patrons' hygiene practices, research is not as plentiful and has yielded mixed results. Past student research has found that the frequency with which someone visits a pool does not positively correlate with knowledge regarding pool hygiene (22). However, a study conducted in Italy indicated that in children and adolescent groups, an increase in frequency of visits to a pool led to healthier pool behaviors (e.g. taking a pre-swim shower). This study also reported that individuals with less knowledge of health risks associated with swimming (e.g. reasons for taking a pre-swim shower) were more likely to adapt unhealthy pool behaviors. Lastly, this study found that reading posted signage did not result in healthy behaviors (23). Instead, research has shown that to change a behavior, education or awareness interventions that focuses on increasing an individual's knowledge of the health risks associated with that behavior are most effective (6). Other studies have also identified that teenagers aged 14-17 are the most likely to exhibit poor pool hygiene, so targeting this population in future educational or awareness campaigns may be beneficial (19).

\section{Research Questions}

As discussed earlier, taking a pre-swim shower is required by the Pool Regulation and is important in keeping pool water safe and comfortable. Given its importance, this study aimed to identify factors associated with a higher pre-swim shower frequency. Factors assessed were knowledge regarding pool related illnesses, knowledge of proper pool hygiene practices, frequency of aquatic facility use, knowledge of what causes the characteristic "chlorine smell" in aquatic facilities, and age. As well, possible association between reading the pool rules and pre-swim shower frequencies were investigated. Lastly, the relationship between knowledge of pool related illnesses and knowledge of good pool hygiene practices was examined.

\section{Materials and Methods}

Hypothesis were investigated using a primary research design and data was gathered using a self-administered electronic survey. The consent form and survey questions were uploaded onto Google Forms. Convenience sampling (24) was then used to invite individuals to participate in the study; these invitations were distributed through Facebook, text message, word of mouth, and email. This was done by composing a short message, which included the link to the survey and sending it through the channels listed. Data was then downloaded from Google Forms, which automatically transferred the data into a Microsoft Excel spreadsheet. An answer key and Microsoft Excel was then used to score sections of the survey. Lastly, all data was analyzed using NCSS 12 (25).

\section{Inclusion and Exclusion}

The criteria for participating in this study was as follows: the individual must have used an aquatic facility before, defined as lap pools, hot tubs, plunge pools, spray parks, water parks, and wading/leisure pools, and must be currently be living or have lived in British Columbia, Canada. Anyone not meeting these two criteria, were excluded from the study. This was done by using the results of two questions in the survey. One question asked individuals how often they used aquatic facilities; those who responded, "I have never used an aquatic facility" were excluded. The second question that was used asked "Do you currently live in or have you lived in the province of British Columbia, Canada?"; those who responded no, were excluded from the study as well. Of the 82 responses, no participants were excluded in this manner.

However, there were participants who were excluded from this study. When distributing the survey through Facebook, the author made it clear that his classmates, second year Environmental Health students at BCIT, should not participate in this study. This was due to the fact that the cohort had just taken the Pools and Recreational Water course and did not have adequate time to adjust their behaviour. It was found, through personal conversation, that some of the author's classmates had participated in the study. By scanning the email addresses of those respondents who wanted to be entered into a draw for a prize, the email addresses of two 
classmates were found; data from these individuals was then discarded. It is unknown if other classmates participated in this study and even if they did, their responses could not be removed as they did not leave their email address. There is no other way to identify which responses belong to them. Lastly, data from two respondents were removed as they did not answer the question "How often do you take a pre-swim shower?" this was because the data from this question was used for all of the hypotheses tested. In total, this study used data from 78 participants.

\section{Ethical Considerations}

In the creation of the study, the beneficence of participants was considered. In completing the survey, no risk or discomfort will befall the individual (26). Conversely, their participation will contribute to scientific knowledge. As well, participation was voluntary and a consent form was provided on Google Forms prior to beginning the survey. This form provided information such as the purpose of the project, that information would be kept confidential, and that the ethics of the study were approved by BCIT.

\section{Description of the Type of Data Collected}

The data collected was nominal data and was either multichotomous nominal or multichotomous ordinal (27). A score for "Part 2: Knowledge on Pool Related Illnesses" and a score for "Part 3: Knowledge - Pool Hygiene" were created (refer to the survey in the Appendix). For each section, questions were graded and then a total score, continuous ratio data (27), was given to each participant.

\section{Statistical Package and Tests Used}

The statistical package used in this study was NCSS 12. The 2017 version of Microsoft Excel for Mac and Google Forms were also used to prepare data for analysis and to generate graphs. The One-Way ANOVA test, Chi-Square test, and the independent t-test was used to analyze data.

\section{Results}

Table 1. Results from hypothesis tested

\begin{tabular}{|l|l|l|l|l|}
\hline $\begin{array}{l}\text { Hypothesis } \\
\text { Number }\end{array}$ & $\mathbf{H}_{\mathbf{0}}$ & $\mathbf{H}_{\mathbf{a}}$ & $\mathbf{P}$-value & Conclusion \\
\hline $\mathbf{1}$ & $\begin{array}{l}\mathbf{H}_{0} \text { there is no difference in the } \\
\text { mean knowledge of pool related } \\
\text { illnesses between individuals who } \\
\text { almost always, occasionally, } \\
\text { and/or rarely/never take a pre- } \\
\text { swim shower. }\end{array}$ & $\begin{array}{l}\mathbf{H}_{\text {a there is a difference in }} \\
\text { the mean knowledge of } \\
\text { pool related illnesses } \\
\text { between individuals who } \\
\text { almost always, } \\
\text { occasionally, and/or } \\
\text { rarely/never take a pre- } \\
\text { swim shower. }\end{array}$ & $\begin{array}{l}\mathrm{p}= \\
0.46437\end{array}$ & $\begin{array}{l}\text { Fail to reject } \mathbf{H}_{0} \text { and conclude } \\
\text { that there is no statistically } \\
\text { significant difference between } \\
\text { the mean knowledge of pool } \\
\text { related illnesses for individuals } \\
\text { who almost always, } \\
\text { occasionally, and/or } \\
\text { rarely/never take a pre-swim } \\
\text { shower. }\end{array}$ \\
\hline $\mathbf{2}$ & $\begin{array}{l}\text { Ho there is no difference in the } \\
\text { mean knowledge of aquatic } \\
\text { facility hygiene between } \\
\text { individuals who almost always, } \\
\text { occasionally, and/or rarely/never } \\
\text { take a pre-swim shower. }\end{array}$ & $\begin{array}{l}\text { Ha there is a difference in } \\
\text { the mean knowledge of } \\
\text { aquatic facility hygiene } \\
\text { between individuals who } \\
\text { almost always, } \\
\text { occasionally, and/or } \\
\text { rarely/never take a pre- } \\
\text { swim shower. }\end{array}$ & 0.14304 & $\begin{array}{l}\text { Fail to reject Ho and conclude } \\
\text { that there is no statistically } \\
\text { significant difference between } \\
\text { the mean knowledge of aquatic } \\
\text { facility hygiene between } \\
\text { individuals who almost always, } \\
\text { occasionally, and/or } \\
\text { rarely/never take a pre-swim } \\
\text { shower. }\end{array}$ \\
\hline
\end{tabular}




\begin{tabular}{|c|c|c|c|c|}
\hline 3 & $\begin{array}{l}\mathbf{H}_{0} \text { there is no association between } \\
\text { how often an individual uses an } \\
\text { aquatic facility and how often } \\
\text { he/she takes a pre-swim shower } \\
\text { (almost always, occasionally, } \\
\text { and/or rarely/never). }\end{array}$ & $\begin{array}{l}\mathbf{H}_{\mathbf{a}} \text { there is an association } \\
\text { how often an individual } \\
\text { uses an aquatic facility } \\
\text { and how often he/she } \\
\text { takes a pre-swim shower } \\
\text { (almost always, } \\
\text { occasionally, and/or } \\
\text { rarely/never). }\end{array}$ & $\begin{array}{l}\mathrm{p}= \\
0.04926\end{array}$ & $\begin{array}{l}\text { Reject } \mathbf{H}_{0} \text { and conclude that } \\
\text { there is a statistically } \\
\text { significant association between } \\
\text { the frequency of aquatic } \\
\text { facility use and the frequency } \\
\text { of taking a pre-swim shower. } \\
\text { There is potential for Type I } \\
\text { error; this type of error can be } \\
\text { minimized by lowering the p- } \\
\text { value cut off to } 0.01 \text {. }\end{array}$ \\
\hline 4 & $\begin{array}{l}\mathbf{H}_{\mathbf{0}} \text { there is no association between } \\
\text { knowing what causes the } \\
\text { "chlorine smell" in aquatic } \\
\text { facilities and how often an } \\
\text { individual takes a pre-swim } \\
\text { shower (almost always and/or } \\
\text { rarely/never). }\end{array}$ & $\begin{array}{l}\mathbf{H}_{\mathbf{a}} \text { there is an association } \\
\text { between knowing what } \\
\text { causes the "chlorine } \\
\text { smell" in aquatic facilities } \\
\text { and how often an } \\
\text { individual takes a pre- } \\
\text { swim shower (almost } \\
\text { always and/or } \\
\text { rarely/never). }\end{array}$ & $\begin{array}{l}\mathrm{p}= \\
0.07016\end{array}$ & $\begin{array}{l}\text { Fail to reject } \mathbf{H}_{0} \text { and conclude } \\
\text { that there is no statistically } \\
\text { significant association between } \\
\text { knowing what causes the } \\
\text { "chlorine smell" in aquatic } \\
\text { facilities and how often an } \\
\text { individual takes a pre-swim } \\
\text { shower. There is potential for } \\
\text { Type II error; this type of error } \\
\text { can be minimized by } \\
\text { increasing the sample size. }\end{array}$ \\
\hline 5 & $\begin{array}{l}\mathbf{H}_{0} \text { there is no association between } \\
\text { an individual's age ( } 45 \text { and under } \\
\text { or over } 45 \text { ) and how often he/she } \\
\text { takes a pre-swim shower (almost } \\
\text { always, occasionally, and/or } \\
\text { rarely/never). }\end{array}$ & $\begin{array}{l}\mathbf{H}_{\text {a }} \text { there is an association } \\
\text { between an individual's } \\
\text { age ( } 45 \text { and under or over } \\
45 \text { ) and how often he/she } \\
\text { takes a pre-swim shower } \\
\text { (almost always, } \\
\text { occasionally, and/or } \\
\text { rarely/never). }\end{array}$ & $\begin{array}{l}\mathrm{p}= \\
0.11947\end{array}$ & $\begin{array}{l}\text { Fail to reject } \mathbf{H}_{0} \text { and conclude } \\
\text { that there is no statistically } \\
\text { significant association between } \\
\text { an individual's age and how } \\
\text { often he/she takes a pre-swim } \\
\text { shower. }\end{array}$ \\
\hline 6 & $\begin{array}{l}\text { Ho there is no association between }_{\text {whether an individual has or has }} \\
\text { not read the pool rules and how } \\
\text { often he/she takes a pre-swim } \\
\text { shower ((i) almost always, (ii) } \\
\text { occasionally, and/or (iii) } \\
\text { rarely/never). }\end{array}$ & $\begin{array}{l}\text { Ha there is an association } \\
\text { between whether an } \\
\text { individual has or has not } \\
\text { read the pool rules and } \\
\text { how often he/she takes a } \\
\text { pre-swim shower ((i) } \\
\text { almost always, (ii) } \\
\text { occasionally, and/or (iii) } \\
\text { rarely/never). }\end{array}$ & $\begin{array}{l}\mathrm{p}= \\
0.69700\end{array}$ & $\begin{array}{l}\text { Fail to reject } \mathbf{H}_{0} \text { and conclude } \\
\text { that there is no statistically } \\
\text { significant association between } \\
\text { whether an individual has or } \\
\text { has not read the pool rules and } \\
\text { how often he/she takes a pre- } \\
\text { swim shower. }\end{array}$ \\
\hline 7 & $\begin{array}{l}\mathbf{H}_{0} \text { the "good pool hygiene } \\
\text { practices" test score for } \\
\text { individuals who scored above the } \\
\text { mean on the "pool related } \\
\text { illnesses knowledge test" is } \\
\text { statistically significantly lower } \\
\text { than the "good pool hygiene } \\
\text { practices" test score for } \\
\text { individuals who scored below the } \\
\text { mean on the "pool related } \\
\text { illnesses knowledge test" }\end{array}$ & $\begin{array}{l}\mathbf{H}_{\text {a the "good pool hygiene }} \\
\text { practices" test score for } \\
\text { individuals who scored } \\
\text { above the mean on the } \\
\text { "pool related illnesses } \\
\text { test" is statistically } \\
\text { significantly greater than } \\
\text { the "good pool hygiene } \\
\text { practices" test score for } \\
\text { individuals who scored } \\
\text { below the mean on the } \\
\text { "pool related illnesses } \\
\text { knowledge test" }\end{array}$ & $\begin{array}{l}\mu 1-\mu 2> \\
0 \\
p=0.017 \\
\text { power }= \\
0.692\end{array}$ & $\begin{array}{l}\text { Reject } \mathbf{H}_{0} \text { and conclude that } \\
\text { the "good pool hygiene } \\
\text { practices" test score for } \\
\text { individuals who scored above } \\
\text { the mean on the "pool related } \\
\text { illnesses knowledge test" is } \\
\text { statistically significantly } \\
\text { greater than the "good pool } \\
\text { hygiene practices" test score } \\
\text { for individuals who scored } \\
\text { below the mean on the "pool } \\
\text { related illnesses knowledge } \\
\text { test". }\end{array}$ \\
\hline
\end{tabular}




\section{Descriptive Statistics}

Data from question 1 of Part 5 - Practices - Pool Hygiene (see Survey in the Appendix) was used in hypotheses 1-6; 37 respondents (47\%) replied that they "almost always take a pre-swim shower", and 17 respondents (22\%) replied that they "occasionally take a pre-swim shower", and 24 participants (31\%) replied that they

"rarely/never take a pre-swim shower". For hypothesis 4, the "occasionally" and "rarely/never" groups were collapsed together.

As for demographics, 67.9\% (53) participants were female, $30.8 \%$ (24) were male, and $1.3 \%$ (1) selected "prefer not to answer". The age distribution was as follows: 9\% (7) were 20-25 years old, 19\% (15) were 26-30 years old, $4 \%$ (3) were $31-35$ years old, $6 \%$ (5) were $36-40$ years old, $5 \%$ (4) were $41-45$ years old, $12 \%$ (9) were $46-50$ years old, $14 \%$ (11) were 51-55 years old, 14\% (11) were 56-60 years old, and $17 \%$ (13) were 60 plus years old.

The overall average score on Part 2: Knowledge on Pool Related Illnesses was 55.29\% and the median score was $58 \%$. This average, $55.29 \%$, was used to divide participants for hypothesis 7 . Participants were either placed in the group "scored above the mean" or "scored below the mean". The average score on Part 3: Knowledge - Pool Hygiene was $69.20 \%$ and the median was $67 \%$. The average scores for each group used in the One-way ANOVA analysis of hypothesis 1 and 2 are shown below.

Table 2. Average score for each knowledge section for each group used in the one-way ANOVA analysis of hypothesis 1 and 2.

\begin{tabular}{|l|c|c|}
\hline \multicolumn{1}{|c|}{ Group } & $\begin{array}{c}\text { Average } \\
\text { Score for } \\
\text { Part 2: } \\
\text { Knowledge } \\
\text { on Pool } \\
\text { Related } \\
\text { Illnesses }\end{array}$ & $\begin{array}{c}\text { Average } \\
\text { Score for } \\
\text { Part 3: } \\
\text { Knowledge - } \\
\text { Pool Hygiene }\end{array}$ \\
\hline $\begin{array}{l}\text { Almost always } \\
\text { takes a pre-swim } \\
\text { shower }\end{array}$ & 0.5286 & 0.7332 \\
\hline $\begin{array}{l}\text { Occasionally takes } \\
\text { a pre-swim shower }\end{array}$ & 0.5482 & 0.6971 \\
\hline $\begin{array}{l}\text { Rarely/never takes } \\
\text { a pre-swim shower }\end{array}$ & 0.5938 & 0.6250 \\
\hline
\end{tabular}

Question 4, "How often do you use an aquatic facility?" from Part 1 - Demographics was used to categorize participants as infrequent, moderate, or frequent users of aquatic facilities. 22 participants (28\%) identified as infrequent users of aquatic facilities (individuals responding, "once a year or less"), 17 participants $(22 \%)$ identified as moderate users of aquatic facilities (individuals responding, "once very few months" or "once every month"), and 39 participants (50\%) identified as frequent users of aquatic facilities (individuals responding, "once every few weeks" or "more than once a week"). Lastly, 57 participants (75\%) replied that they have read the pool rules and 19 participants $(25 \%)$ replied that they have not read the pool rules.

\section{Discussion}

The main goal of this study was to gain a better understanding of the factors affecting the preswim showering frequency of patrons using aquatic facilities. It was postulated that greater knowledge about pool related illnesses and or proper pool hygiene would be associated with greater pre-swim shower frequency.

Presumably, knowledgeable patrons understand the importance of pre-swim showers in preventing illness and keeping the pool environment comfortable and would be more inclined to take pre-swim showers. The results indicate that there is no statistically significant association between these variables and a patron's pre-swim shower frequency. Interestingly, the data generated did show that those who scored higher on the knowledge of pool related illnesses section also scored higher on the pool hygiene section. This suggests that, in this instance, greater theoretical knowledge does lead to greater practical knowledge but, as described above, greater knowledge does not seem to lead to better practices. Overall, these results are in contrast to research conducted in Italy, which showed that individuals with less knowledge of health risks associated with swimming (e.g. reasons for taking a pre-swim shower) were more likely to adapt unhealthy pool behaviours (23). However, the results do align with research conducted on the 
effectiveness of education and awareness interventions such as campaigns aimed at decreasing salt intake. Research has shown that alone, these interventions were not very successful in lowering salt intake within populations (21).

The results of this study indicated that there was no statistically significant difference between different age groups in pre-swim shower frequency, which is in contrast to a study conducted in Italy, which showed that teenagers aged 14-17 were most likely to exhibit poor pool hygiene (19). However, it is worth noting that respondents of this study did not fall within the 14-17 age range. Another result that contrasts with existing literature is that a previous study by Gallè et al. found that an increase in the frequency of visits to a pool led to healthier pool behaviors, which included taking a pre-swim shower (23). This study did find a statistically significant association between facility use and frequency of taking a pre-swim shower. However, the reverse was found; frequent aquatic facility users made up the largest proportion of individuals who rarely/never took a pre-swim shower. There was an even distribution of frequent, moderate, and infrequent users making up those who always took a pre-swim shower and those who occasionally took a pre-swim shower. This difference could be due to a high percentage of respondents being members of the same swim club as the research supervisor; this club uses a facility with very cold showers and as will be explained below, this is a deterrent to taking a pre-swim shower. The extent of this issue cannot be accessed as the identities of the participants were kept confidential.

The data also suggests that there is no association between having read the pool rules and pre- swim shower frequency. This result is in agreement with one study (19) but not with another (23), both of which were done in Italy. The contrasting results may be due to cultural differences, as even within a country, different geographical regions may differ culturally. The result in this study may be explained by looking at responses to the question "swimmer hygiene could be improved if'. Here, $48.7 \%$ responded if "rules were made clearer" and another $42.3 \%$ selected if "more signage was posted". So perhaps, if wording on signage was improved and if they were placed in more appropriate locations, pool hygiene could be improved.

A study conducted in the United States of America found that $32 \%$ of American's shower before entering the pool (20), whereas this study found that $47 \%$ of respondents almost always took a pre-swim shower. As for ways to increase pre-swim shower frequency, the top responses for the American study were if showers were more accessible $(31 \%)$, private $(35 \%)$ and or clean $(38 \%)$. In this study, the top factors were if the shower water was warmer $(55.6 \%)$ and if the showers were cleaner $(33.3 \%)$ and more private $(31.9 \%)$. As well as if there were consequences or penalties for not showering $(31.9 \%)$. Study participants indicated that overall swimmer hygiene could be improved if the design/layout of the facility encouraged showering $(53.8 \%)$ and if there was greater enforcement and consequences were implemented (52.6\%).

\section{Limitations}

One limitation of this study was that data was collected through a self-administered electronic survey. Using convenience sampling (24) such as this presents challenges in being able to generalize the findings to British Columbians as a whole. As well, this method generated 78 responses but a higher sample size would help to increase external validity (26). As discussed above, a large proportion of respondents could have been swim club members (both from the research supervisor's connections and the author's connections), which would affect external validity. It has been noted in a study that swim club participants do not have great pool hygiene (13), so this may have affected results as well. Lastly, it was found that some of the author's classmates had responded to the survey. Those who could be identified through e-mail addresses (left to be entered into a draw for a prize) were removed but it is possible that not all of the author's classmates were excluded. This may affect external validity as the author's classmates would have high knowledge in this subject area but would not have had enough time to adjust their behaviours. 
Although study participant's overall knowledge on pool related illnesses and pool hygiene were accurately assessed through the use of valid sources of information on recreational water illnesses $(3,5,10)$, the internal validity of the study in terms of measuring knowledge on why pre-swim showers are necessary was lacking. For example, one question asked about the cause of the "chlorine smell" in pools. Possible answers included "too much chlorine", "disinfection by-products", or "the mixture of chemicals used". It was found that there was no association between knowing the answer to this question and pre-swim shower frequency. Even if respondents selected the correct answer (disinfection by-products), this does not truly assess if respondents understand the importance of pre-swim showers. Questions should have been included to assess if participants understood the reasons why pre-swim showers are important to pool hygiene. For example, questions should have been created to assess the following line of reasoning; pre-swim showers reduce the amount of contaminants added to water, which in turn decreases disinfection byproduct formation, which in turn leads to less of a "chlorine smell" in pools and greater user comfort.

This study could be improved if an in-person self-administered survey was used. As there are a wide variety of aquatic facilities around the Metro Vancouver area, facilities could be selected (to conduct surveys at) in order to gain a good representation of facilities in Metro Vancouver. This would increase external validity as the issue of having a majority of respondents coming from a facility with cold or dirty showers would be avoided. An alternative solution would be to ask respondents which facilities they go to so that any facility related issues affecting swimmer hygiene could be investigated. As well, as discussed above, the questionnaire should be altered to better assess if respondents know why pool hygiene practices are important in preventing pool related illnesses and keeping the pool environment enjoyable for all patrons. These changes would increase internal validity as it would allow a more accurate assessment of if greater knowledge leads to better pool hygiene practices.

\section{Knowledge Translation}

The results suggest that greater knowledge about pool related illnesses or good pool hygiene practices does not lead to an increase in preswim shower frequency. However, as discussed in the limitations section of this paper, the internal validity may be lacking. Therefore, this study should not be used to assess the validity of using educational campaigns to improve the hygiene of aquatic facility users. Where this study may possibly contribute to bettering public health is in changing guidelines for pool construction. One of the survey questions asked respondents what would encourage them to take pre-swim showers more often and the most selected response was "if the water was warmer" $(55.6 \%)$. Section 5.3 of the B.C. Guidelines for Pool Design (28) does address the temperature of shower water but perhaps, an amendment could be added that showers be able to provide hot water within a certain time frame after being turned on. As after speaking with the research supervisor, it was brought to the author's attention that this is an issue in some facilities. As well, a section within the guideline could be added to encourage the construction of showers that were more private (perhaps by creating individual stalls or installing curtains). This was cited by $31.9 \%$ of respondents as a factor in if they would take a pre-swim shower more often. The guideline does address designing facilities so that showering is facilitated but facility design/layout was still sighted by $53.8 \%$ of respondents as a way to improve swimmer hygiene. Perhaps the use of showers that automatically spray patrons as they exit the change room to the pool deck could be explored.

This study could also help to change the policies of aquatic facility workers. As was previously mentioned, study participants cited that pool hygiene could be improved if the rules were clearer, there was more signage, and if there was greater enforcement of rules or there were consequences for not following them. One way this may happen is if aquatic staff such as lifeguards reminded patrons to take pre-swim showers before entering the pool. Staff could be 
incentivized to do this if they were made aware if more patrons were to take pre-swim showers, they may receive fewer complaints of the pool having a strong "chlorine smell".

\section{Future Research}

Future projects could include repeating this project using an in-person self-administered survey that asks questions that specifically assess if respondents know why certain pool hygiene practices are important. The goal being to understand the relationship between knowledge of why a certain hygiene practice is important and the actual practice itself. Another could be to assess the pool hygiene practices of different types of users (i.e. competitive swimmers, those in swimming lessons, recreational swimmers, etc.). This could help inform policy makers on which group to target when implementing interventions to improve their pool hygiene. Lastly, study participants stated that they would take more pre-swim showers if the showers were cleaner. The cleaning frequency and procedures of aquatic facilities could be assessed to create a cleanliness score for the facility. The patrons of these facilities could be surveyed about their pre-swim shower frequencies. This study would investigate if the cleanliness of a shower area affects a patron's pre-swim shower frequency.

\section{Conclusion}

Summarizing the hypothesis tested in this study, it was found that knowledge about pool related illnesses and good swimmer hygiene did not affect pre-swim shower frequency. As discussed above, the survey questions may lack strong internal validity and results should be interpreted accordingly. An individual's age and if they had read the pool rules also did not have a connection to pre-swim shower frequency. There was an association found between how often an individual uses aquatic facilities and their pre-swim shower frequency. However, it was counter intuitive as it was found that those who rarely/never take a pre-swim shower are more likely to be individuals who are frequent users of aquatic facilities. As discussed in this paper, this may be due to the fact that, potentially, a large proportion of respondents came from the research supervisor's swim club which swims at a pool where the showers do not run hot. Overall, this project can be seen as more of a preliminary study for data gathering. It did highlight that if showers were cleaner, warmer, and or more private, pre-swim shower frequency might increase. As well, greater enforcement of pool rules may increase pre-swim shower frequencies as $79.5 \%$ of participants knew that taking a pre-swim shower is required before entering the pool as is stated in the B.C. Pool Regulation (2).

\section{Acknowledgments}

The author would like to thank Helen Heacock for her guidance and for her help in distributing the survey for this study.

\section{Competing Interests}

The author declares that they have no competing interests.

\section{References}

1. Canadian Heritage. Sport Participation 2010 [Internet]. 2013. 1-131 p. Available from:

http://publications.gc.ca/collections/colle ction_2013/pc-ch/CH24-1-2012-eng.pdf

2. Queen's Printer. Pool Regulation [Internet]. 2012. Available from: http://www.bclaws.ca/civix/document/id/ loo92/loo92/296_2010

3. Centers for Disease Control and Prevention. Swimmer Hygiene [Internet]. 2017. Available from: https://www.cdc.gov/healthywater/hygie ne/swimming/index.html

4. Keuten MGA, Schets FM, Schijven JF, Verberk JQJC, van Dijk JC. Definition and quantification of initial anthropogenic pollutant release in swimming pools. Water Res [Internet]. 2012;46(11):3682-92. Available from: http://dx.doi.org/10.1016/j.watres.2012.0 
4.012

5. Foundation NSP. Pool and Spa Operator Handbook. Colorado Springs, CO: National Swimming Pool Foundation; 2017. 35-48 p.

6. Michie S, Johnston M. Changing clinical behaviour by making guidelines specific. BMJ [Internet]. 2004;343-5. Available from: https://www.bmj.com/content/328/7435/ 343.full

7. Sanborn M, Takaro T. Recreational water - related illness. Canadian Family Physician. 2013;59:491-5.

8. Castor ML, Beach MJ. Reducing Illness Transmission From Disinfected Recreational Water Venues. Pediatr Infect Dis J [Internet]. 2004;23(9):86670. Available from:

http://content.wkhealth.com/linkback/ope nurl?sid=WKPTLP:landingpage $\& a n=00$ 006454-200409000-00018

9. Michelle C. Hlavsa, Virginia A. Roberts, Amy M. Kahler, Elizabeth D. Hilborn, Taryn R. Mecher, Michael J. Beach, Timothy J. Wade JSY. Outbreaks of Illness Associated with Recreational Water - United States, 2011-2012. 2015;64(24).

10. Centers for Disease Control and Prevention. Recreational Water Illnesses [Internet]. 2017. Available from: https://www.cdc.gov/healthywater/swim ming/swimmers/rwi.html

11. Centers for Disease Control and Prevention. Legionella (Legionnaires' Disease and Pontiac Fever) [Internet]. 2017. Available from: https://www.cdc.gov/legionella/about/cau ses-transmission.html

12. Centers for Disease Control and Preventio Morbidity and Mortality Weekly Report. Microbes in Pool Filter Backwash as Evidence of the Need for Improved Swimmer Hygiene - MetroAtlanta, Georgia, 2012. JSTOR. 2017;62(19):385-8.

13. Lakind JS, Richardson SD, Blount BC. The good, the bad, and the volatile: Can we have both healthy pools and healthy people? Environ Sci Technol.
2010;44(9):3205-10.

14. Boskabady M, Esmaeilizadeh M, Boskabady M. The effect of exposure to chlorine on pulmonary function tests and respiratory and allergic symptoms in Iranian lifeguards. Toxicol Ind Health [Internet]. 2014;30(3):218-24. Available from:

http://journals.sagepub.com/doi/10.1177/ 0748233712454465

15. Massin N, Bohadana AB, Wild P, Hery M, Toamain JP, Hubert G. Respiratory symptoms and bronchial responsiveness in lifeguards exposed to nitrogen trichloride in indoor swimming pools. Occup Environ Med [Internet]. 1998;55(4):258-63. Available from: http://oem.bmj.com/cgi/doi/10.1136/oem. 55.4.258

16. Environmental Public Health Monitor. Swimming, Chlorine...and Asthma? 2007;9(2):1-4.

17. Bernard A, Carbonnelle S, Michel O, Higuet S, De Burbure C, Buchet JP, et al. Lung hyperpermeability and asthma prevalence in schoolchildren: unexpected associations with the attendance at indoor chlorinated swimming pools. Occup Env Med [Internet]. 2003;60(6):385-94.

Available from:

http://www.ncbi.nlm.nih.gov/pmc/article s/PMC1740550/pdf/v060p00385.pdf

18. Ferrari M, Schenk K, Mantovani W, Papadopoulou C, Posenato C, Ferrari P, et al. Attendance at chlorinated indoor pools and risk of asthma in adult recreational swimmers. J Sci Med Sport [Internet]. 2011;14(3):184-9. Available from:

http://dx.doi.org/10.1016/j.jsams.2010.12 .006

19. Pasquarella C, Veronesi L, Napoli C, Castaldi S, Pasquarella ML, Saccani E, et al. What about behaviours in swimming pools? Results of an Italian multicentre study. Microchem J [Internet]. 2014;112:190-5. Available from: http://dx.doi.org/10.1016/j.microc.2013.0 9.024

20. Wiant C. New public survey reveals swimmer hygiene attitudes and practices. 
Int J Aquat Res Educ. 2012;6(3):201-2.

21. Trieu K, McMahon E, Santos JA, Bauman A, Jolly K-A, Bolam B, et al. Review of behaviour change interventions to reduce population salt intake. Int J Behav Nutr Phys Act [Internet]. 2017;14(1):17. Available from:

http://ijbnpa.biomedcentral.com/articles/ 10.1186/s12966-017-0467-1

22. Chan E, Macleod M. A Comparison of Recreational Water Illness Awareness and Frequency of Swimming. BCIT Environmental Health Journal [Internet]. 2014;1-12. Available from: https://circuit.bcit.ca/repository/islandora /object/repository\%3A17

23. Gallè F, Dallolio L, Marotta M, Raggi A, Di Onofrio V, Liguori G, et al. Healthrelated behaviors in swimming pool users: Influence of knowledge of regulations and awareness of health risks. Int J Environ Res Public Health.
2016;13(5).

24. Methodology R. Convenience sampling [Internet]. 2017. Available from: https://researchmethodology.net/sampling-in-primarydata-collection/convenience-sampling/

25. NCSS. NCSS 12 Update [Internet]. 2018. Available from:

https://www.ncss.com/download/ncss/up dates/ncss-12/

26. Heacock H. Research methods, Research design and data collection [lecture notes]. 2017.

27. Heacock H. Research methods, Introduction to descriptive statistics [lecture notes]. 2017.

28. Ministry of Health. B.C. Guidelines for Pool Design [Internet]. 2014. Available from:

https://www2.gov.bc.ca/assets/gov/envir onment/air-land-

water/pool_design_guidelines_jan_2014_ final.pdf 